Original Article

\title{
Effects of Kinesio taping and Mcconnell taping on balance and walking speed of hemiplegia patients
}

\author{
Yong-Kyu Choi ${ }^{1)}$, Young-Han PARK ${ }^{2)}$, Jung-Ho LeE ${ }^{3)^{*}}$ \\ 1) Department of Physical Therapy, Graduate School of Physical Therapy, Daegu University, Republic \\ of Korea \\ 2) Department of Physical Therapy, Korea National University of Transportation, Republic of Korea \\ 3) Department of Physical Therapy, KyungdongUniversity: Bongpo-ri, Toseong-myeon, Goseong-gun, \\ Gangwon-do, Republic of Korea
}

\begin{abstract}
Purpose] The aim of this study was to evaluate the overlap effect of the PNF following the application of Kinesio taping and the McConnell taping, and also the impact of the taping application method on the balance and walking speed of the patients with stroke. [Subjects and Methods] Thirty-six patients who were diagnosed with hemiplegia due to stroke were selected as subjects of this study. They were randomly and evenly divided into experiment group 1 (Kinesio taping group), experiment group 2 (McConnell taping group), and the control group; each group had 12 patients. [Results] The Berg balance scale (BBS) was used to evaluate balance, and the ability in this study. A $10 \mathrm{~m}$ walking test (10MWT) was performed to measure the walking speed. Experiment group 1 showed a statistically significant improvement in balance and walking speed compared to experiment group 2, and the control group in week 4 and week 8. [Conclusion] Application of Kinesio taping had a more beneficial effect on the balance and walking speed than joint-fixation taping of the patients with stroke.

Key words: Stroke, Balance, Walking speed
\end{abstract}

(This article was submitted Nov. 19, 2015, and was accepted Dec. 23, 2015)

\section{INTRODUCTION}

Stroke is described as a neurologic disease that suddenly occurs due to the loss of brain function resulting from an abnormal decrease in the blood supply ${ }^{1)}$. With its high occurrence rate, stroke is one of the major causes of death worldwide ${ }^{2)}$. Stroke is the second most common disease in advanced countries, and is a major cause of impairment among adults. Although there are a few cases where the patients with stroke show a normal walking pattern ${ }^{3}$, most patients with stroke are incapable of normal walking due to defects in posture, tonus of muscle, motion coordination, etc ${ }^{4}$.

Patients with stroke, who support approximately $30-40 \%$ of their body weight on the paralyzed side, face diverse problems, such as a decrease in balance ability because of unstable left and right balance and postural control, as well as a decrease in exercise ability ${ }^{5}$. Balance degradation of patients with stroke is usually caused by a reduction in postural control and joint movement ability, impairment of proprioceptive sense, and weakening of muscle strength.

One of the treatment mothods that is frequently used in clinics is the Kinesio taping technique. Clinically, the Kinesio taping technique is frequently used in orthopedic medicine, sports medicine, and nerve-root rehabilitation ${ }^{6}$. In previous research, the application of Kinesio taping has been reported to improve patients' functional usage and reduce their pain ${ }^{7)}$, and increase the bio-electric activity of the vastus medialis ${ }^{8)}$. Kinesio taping is used to reduce the pressure on the joint that is created during walking and muscle-strength reinforcing exercises, and to stimulate muscle activity and proprioceptive

*Corresponding author. Jung-Ho Lee (E-mail: 1jhcivapt@naver.com)

(C2016 The Society of Physical Therapy Science. Published by IPEC Inc.

This is an open-access article distributed under the terms of the Creative Commons Attribution Non-Commercial No Derivatives (by-nc-nd) License $<$ http://creativecommons.org/licenses/by-nc-nd/4.0/>. 
sense $^{9}$. It has been reported that the application of Kinesio taping is effective at improving the balance and walking speed of hemiplegia patients ${ }^{10}$.

Most of the recent studies of hemiplegia patients have investigated the effects of both non-elastic taping and elastic taping. Studies that have applied each type of taping before exercise treatment are rare. Hence, this study not only examined the overlap effect of PNF following joint-fixating non-elastic taping and proprioceptor-stimulating elastic taping, but also examined the impact of the taping application method on the balance and walking speed of patients with stroke.

\section{SUBJECTS AND METHODS}

\section{Subjects}

The subjects of this study were 36 in patients of C Hospital in Cheong-ju who were diagnosed with hemiplegia due to a stroke. The inclusion criteria for the study were as follows: patients who had been diagnosed with stroke more than six months previously, patients with MMSE-K (Mini-mental state examination Korean version) scores over 21, patients with Modified Ashworth Scale scores of less than 2, patients with no musculoskeletal disease in either the upper or lower extremities, and patients who voluntarily agreed to participate after listening to an explanation of the experimental procedure. Patients excluded from the study were those who had had replacement arthroplasty in a lower limb joint or had experienced a fracture, those who could not correctly perform the PNF pattern, those with mental disorders or who were under psychoactive medication, and those who experienced allergic skin reactions to the tape.

The research subjects were randomly and evenly divided into experiment group 1, experiment group 2, and the control group; each group had 12 patients. Experiment group 1 patients had proprioceptor-stimulating elastic taping applied before performing the PNF technique, while experiment group 2 patients had joint-fixating non-elastic taping applied before performing the PNF technique. The control group only performed the PNF technique applied. After sufficient explanation of the purpose and procedures of the study, voluntary consent was obtained from the subjects before the experiments were initiated. The participants were provided a written informed consent form in accordance with the ethical principles of the Declaration of Helsinki. All of the subjects stated that they understood the purpose of the research.

\section{Methods}

Balance and walking speed were evaluated before the intervention, and after 4 and 8 weeks of the intervention. All of the evaluations were conducted directly by the researchers. The intervention therapy was performed for 30 minutes, three times a week, for a total of 8 weeks (24 times). The Berg balance scale (BBS) was used to evaluate balance, and the 10MWT was performed to measure the walking speed.

In experiment group 1, Kinesio taping was applied to the rectus femoris muscle and the tensor fasciae latae of the hemiplegia patients' affected side. Following to Kim et al., the tuberosity of the tibia below the knee joint to the inferior anterior iliac spine (approximately $45 \mathrm{~cm}$ ) was covered using Kinesio tape with a width of $5 \mathrm{~cm}^{11)}$. In experiment group 2, taping was applied while the subjects slightly bent the knee joint. A $3.8 \mathrm{~cm}$ non-elastic taping was used. The taping application followed the method in which the transverse tape of the upper part was applied from the lateral kneecap and was pulled from the outside to the inside to cover the rear medial semitendinous muscle ${ }^{12)}$.

For PNF the subjects lay in the supine position and began with a posture of the hip joint in extension-abduction-internal rotation, the knee in extension, the ankle in plantar flexion-eversion, and the toe in flexion, and then changed the pattern to a posture of the hip in flexion-adduction-external rotation, the knee in flexion, the ankle in dorsiflexion-inversion, and the toe in extension. Then they performed the opposite pattern to return to the original posture. Each pattern of the PNF technique was performed for 5 minutes, and a 3-minute rest time was provided between the different patterns. The PNF pattern was performed for 30 minutes a day, three times a week for 8 weeks (a total of 24 times). Evaluation and PNF treatment were performed by a physical therapist with 10 years of experience.

One-way ANOVA was conducted for comparitive analysis of the groups in each period regarding the normality, the balance, and the walking speed. The least squares difference was used as a post-hoc test. For statistical processing, the PASW Win. 20 package was used, and significance was accepted for values of $\mathrm{p}<0.05$.

\section{RESULTS}

This study used the BBS to assess the patients' balance ability. The initial evaluation was performed before applying the taping, and the measured value of each group was used in a homogeneity test $(p>0.05)$. All three groups showed increasing BBS scores as time went by. Experiment group 1 showed a statistically significant improvement in balance ability compared to experiment group 2, and the control group in week 4 and week $8(\mathrm{p}<0.05)$ (Table 1).

The 10MWT was used to evaluate walking speed. A homogeneity test was conducted using the measured values of the walking speed $(\mathrm{p}>0.05)$. Statistically significant between-group differences in 10MWT were observed in week 4 and week $8(\mathrm{p}<0.05)$. In the post-hoc test, it was confirmed that the walking speed of experiment group 1 was significantly higher than that of the control group in week 4 and week 8 . 
Table 1. Caomparison of BBS and 10MWT among the groups

\begin{tabular}{llccc}
\hline Group & & Experimental group 1 & Experimental group 2 & Control group \\
\cline { 3 - 5 } & & Mean \pm SD & Mean \pm SD & Mean \pm SD \\
\hline BBS & pre-test & $36.4 \pm 3.5$ & $33.7 \pm 3.1$ & $34.4 \pm 4.6$ \\
(score) & 4 week* & $39.1 \pm 3.6$ & $34.5 \pm 3.2$ & $34.8 \pm 4.8$ \\
& 8 week* & $39.7 \pm 3.6$ & $34.8 \pm 3.4$ & $35.1 \pm 5.2$ \\
10MWT & pre-test & $29.5 \pm 8.8$ & $35.4 \pm 16.2$ & $42.1 \pm 13.5$ \\
(second) & 4 week* & $26.9 \pm 9.1$ & $34.5 \pm 15.5$ & $41.6 \pm 13.6$ \\
& 8 week* & $24.0 \pm 9.3$ & $33.7 \pm 15.0$ & $40.4 \pm 13.8$ \\
\hline \multicolumn{2}{l}{ BBS: Berg balance scale; 10MWT: ten-meter walking time }
\end{tabular}

BBS: Berg balance scale; 10MWT: ten-meter walking time

$* \mathrm{p}<0.05$, one-way ANOVA

\section{DISCUSSION}

Patients with stroke show a very large postural disturbance in the standing position, and place more weight on the unaffected side than on the affected side. This kind of asymmetry impairs balance, walking, and various other functions ${ }^{12}$. Balance is the ability to maintain the balance of body, and it is one of the body functions that maintains body stability, an important factor in daily life ${ }^{13)}$. Balance is affected by a variety of factors, such as biodynamics, and it involves the integration of the visual system with the somatic nervous system, muscle strength, the ROM of joints, and the motor control ability of the myotonus ${ }^{14}$.

In this study, BBS showed between-group differences after 4 weeks of treatment. Experiment group 1 showed significant increases in the BBS score at the end of week 4 and week 8 compared to experiment group 2 and the control group. These results can be explained by the taping application before therapy having stimulated muscle activation and proprioceptive sense, which subsequently improved balance ability. Aytar et al. applied Kinesio taping to 22 patients with patellofemoral pain symptoms in the acute phase, to examine its impact on the patients' pain, strength, muscle strength, and balance ${ }^{15)}$. In an evaluation of all of the patients after the intervention, the group that had received Kinesio taping showed a more significant increase in static balance and dynamic balance measurements than the control group.

According to Walker et al., the walking speed increases from $0.42 \mathrm{~m} / \mathrm{sec}$ at the early stage of stroke to $0.79 \mathrm{~m} / \mathrm{sec}$ after 3 months. The minimum gait velocity required for daily life, such as walking on a footpath, is reported to be $0.74 \mathrm{~m} / \mathrm{s}^{16}$. Brandstater et al. argued that the walking speed of comfortable patients with stroke is $0.75 \mathrm{~m} / \mathrm{s}$, which is $46 \%$ slower than the $1.38 \mathrm{~m} / \mathrm{s}$ of normal people ${ }^{17}$.

In this study, walking speed was measured using the 10MWT, and it showed between differences at groups in week 4 and week 8 . The post-hoc test results revealed significant difference in experiment group 1 and the control group at week 4 and week 8 . Experiment group 1 showed a significant increase in walking speed compared to the control group, which can be attributed to activation of the muscle by the taping and an increase in stride length due to stimulation of the proprioceptive sense, Song et al. examined the walking speed of hemiplegia patients after applying Kinesio taping. They reported there was a significant increase in the walking speed, cadence, and stride length in the group that had Kinesio taping applied to the affected side gluteus medius, gluteus maximus, usculus psoas major, tibialis anterior, transversus abdominis, and their result is consistent with the results of this study ${ }^{10)}$.

There were a few limitations to this study. Among the patients that were hospitalized in Hospital C located in Cheongju, only those who satisfied the research conditions were used as research subjects. Hence, it is difficult to generalize these study results to all hemiplegia patients. There is a possibility of allergy when applying taping to patients with hemiplegia after stroke who have sensitive skin. Also, during the research period, patients often complained of fatigue, and placebo effects were not considered. More diverse research will be required in the future, to address the limitations of this study, and to evaluate the effects of the taping method on patients with stroke.

\section{REFERENCES}

1) Gatti MA, Portela M, Gianella M, et al.: Walking ability after stroke in patients from Argentina: predictive values of two tests in subjects with subacute hemiplegia. J Phys Ther Sci, 2015, 27: 2977-2980. [Medline] [CrossRef]

2) Komolafe MA, Ogunlade O, Komolafe EO: Stroke mortality in a teaching hospital in South Western Nigeria. Trop Doct, 2007, 37: 186-188. [Medline] [CrossRef]

3) Jørgensen HS, Nakayama H, Raaschou HO, et al.: Recovery of walking function in stroke patients: the Copenhagen Stroke Study. Arch Phys Med Rehabil, 1995, 76: 27-32. [Medline] [CrossRef] 
4) Lee KH: The role of compensatory movements patterns in spontaneous recovery after stroke. J Phys Ther Sci, 2015, 27: 2671-2673. [Medline] [CrossRef]

5) Horstman AM, Beltman MJ, Gerrits KH, et al.: Intrinsic muscle strength and voluntary activation of both lower limbs and functional performance after stroke. Clin Physiol Funct Imaging, 2008, 28: 251-261. [Medline] [CrossRef]

6) Yasukawa A, Patel P, Sisung C: Pilot study: investigating the effects of Kinesio Taping in an acute pediatric rehabilitation setting. Am J Occup Ther, 2006, 60: 104-110. [Medline] [CrossRef]

7) Jaraczewska E, Long C: Kinesio taping in stroke: improving functional use of the upper extremity in hemiplegia. Top Stroke Rehabil, 2006, 13: 31-42. [Medline] [CrossRef]

8) Słupik A, Dwornik M, Białoszewski D, et al.: Effect of Kinesio Taping on bioelectrical activity of vastus medialis muscle. Preliminary report. Ortop Traumatol Rehabil, 2007, 9: 644-651. [Medline]

9) Ho YH, Lin CF, Chang CH, et al.: Effect of ankle kinesio taping on vertical jump with run-up and countermovement jump in athletes with ankle functional instability. J Phys Ther Sci, 2015, 27: 2087-2090. [Medline] [CrossRef]

10) Song MH, Jeon BS, Cho CO, et al.: Effect of kinesio taping application on balance and gait ability in hemiplegic disables after cerebral stroke. J Adapted Phys Act Exerc, 2008, 16: 143-159. [CrossRef]

11) Kim DY, Seo BD: Immediate effect of quadriceps kinesio taping on the anaerobic muscle power and anaerobic threshold of healthy college students. J Phys Ther Sci, 2012, 24: 919-923. [CrossRef]

12) Nichols DS, Glenn TM, Hutchinson KJ: Changes in the mean center of balance during balance testing in young adults. Phys Ther, 1995, 75: 699-706. [Medline]

13) Ko Y, Ha H, Bae YH, et al.: Effect of space balance 3D training using visual feedback on balance and mobility in acute stroke patients. J Phys Ther Sci, 2015, 27: 1593-1596. [Medline] [CrossRef]

14) Horak FB, Henry SM, Shumway-Cook A: Postural perturbations: new insights for treatment of balance disorders. Phys Ther, 1997, 77: 517-533. [Medline]

15) Aytar A, Ozunlu N, Surenkok O, et al.: Initial effects of kinesio taping in patients with patellofemoral pain syndrome: a randomized, double-blind study. Isokinet Exerc Sci, 2011, 19: 135-142.

16) Walker C, Brouwer BJ, Culham EG: Use of visual feedback in retraining balance following acute stroke. Phys Ther, 2000, 80: 886-895. [Medline]

17) Brandstater ME, de Bruin H, Gowland C, et al.: Hemiplegic gait: analysis of temporal variables. Arch Phys Med Rehabil, 1983, 64: 583-587. [Medline] 